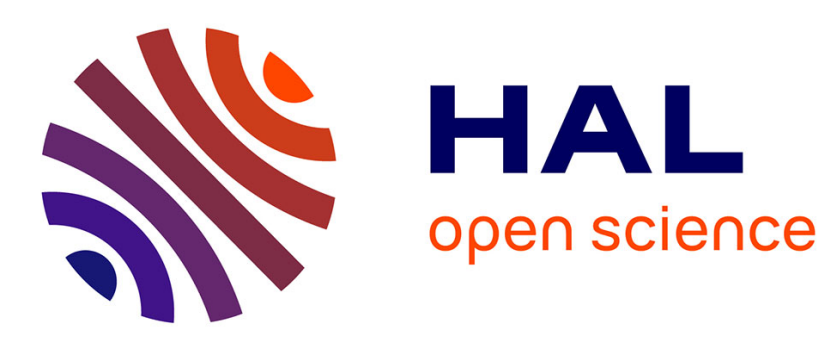

\title{
Bounded Cumulative Prospect Theory: Some Implications for Gambling Outcomes
}

David Peel

\section{To cite this version:}

David Peel. Bounded Cumulative Prospect Theory: Some Implications for Gambling Outcomes. Applied Economics, 2008, 40 (01), pp.5-15. 10.1080/00036840701728765 . hal-00582278

\section{HAL Id: hal-00582278 \\ https://hal.science/hal-00582278}

Submitted on 1 Apr 2011

HAL is a multi-disciplinary open access archive for the deposit and dissemination of scientific research documents, whether they are published or not. The documents may come from teaching and research institutions in France or abroad, or from public or private research centers.
L'archive ouverte pluridisciplinaire HAL, est destinée au dépôt et à la diffusion de documents scientifiques de niveau recherche, publiés ou non, émanant des établissements d'enseignement et de recherche français ou étrangers, des laboratoires publics ou privés. 


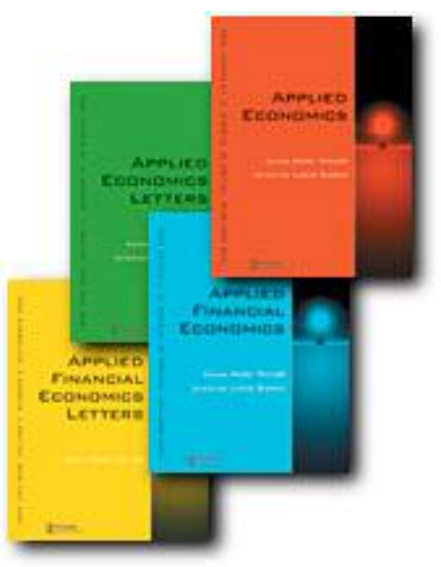

Bounded Cumulative Prospect Theory: Some Implications for Gambling Outcomes

\begin{tabular}{|c|c|}
\hline Journal: & Applied Economics \\
\hline Manuscript ID: & APE-07-0712 \\
\hline Journal Selection: & Applied Economics \\
\hline $\begin{array}{r}\text { Date Submitted by the } \\
\text { Author: }\end{array}$ & 03-Oct-2007 \\
\hline Complete List of Authors: & Peel, David; University of Lancaster, Economics \\
\hline JEL Code: & $\begin{array}{l}\text { C72 - Noncooperative Games \&lt; C7 - Game Theory and } \\
\text { Bargaining Theory \&lt; C - Mathematical and Quantitative Methods }\end{array}$ \\
\hline Keywords: & gambling \\
\hline
\end{tabular}

\section{(5) ScholaroNE" \\ Manuscript Central}




\title{
Bounded Cumulative Prospect Theory: Some Implications for Gambling Outcomes
}

\author{
Michael Cain ${ }^{1}$, David Law, ${ }^{1, *}$ and David A. Peel ${ }^{2}$
}

\begin{abstract}
Standard parametric specifications of Cumulative Prospect theory (CPT) can explain why agents bet on longshots at actuarially unfair odds. However the standard specification of CPT cannot explain why people might bet on more favored outcomes, where by construction the greatest volume of money is bet. This paper outlines a parametric specification than can consistently explain gambling over all outcomes. In particular we assume that the value function is bounded from above and below and that the degree of loss aversion experienced by the agent is smaller for small-stake gambles (as a proportion of wealth) than usually assumed in CPT. There are a number of new implications of this specification. Boundedness of the value function in CPT implies that the indifference curve between expected-return and win-probability for a given stake will typically exhibit both an asymptote (implying rejection of an infinite gain bet) and a minimum, as the shape of the value function dominates the probability weighting function. Also the high probability section of the indifference curve will exhibit a maximum.
\end{abstract}

Keywords: Cumulative Prospect Theory; Exponential Value Function; Gambling

JEL classification: C72; C92; D80; D84

${ }^{1}$ University of Wales Bangor, ${ }^{2}$ University of Lancaster

*Corresponding author. E-mail address: d.law@bangor.ac.uk Telephone:

01248382172, School for Business and Regional Development, University of Wales, Bangor, Gwynedd LL57 2DJ, United Kingdom. 


\section{Bounded Cumulative Prospect Theory: Some Implications for Gambling Outcomes ${ }^{i}$}

\section{Introduction}

Original Prospect theory (OPT), proposed by Kahneman and Tversky (1979), and Cumulative Prospect theory (CPT) as proposed by Starmer and Sugden (1989) and Tversky and Kahneman (1992) is able to resolve the Allais paradox [see e.g. Allais and Hagen (1979)] and also explains a variety of experimental evidence which is inconsistent with standard expected-utility theory [see e.g. Starmer (2000), Rabin (2000), Rabin and Thaler (2001), and Thaler (1985)]. ii

It is also claimed that CPT can explain outcomes in gambling markets For instance. Kahneman and Tversky (1979), note that CPT predicts insurance and gambling for small probabilities but state that "the present analysis falls far short of a fully adequate account of these complex phenomena". This appears to be the case. With the standard parametric specifications, gambling on longshots at actuarially unfair odds can optimally occur, but betting on 50/50 and odds-on chances cannot. Given that most of the money bet is on favourites many would argue CPT as currently constructed has not provided an explanation of outcomes observed in gambling markets [see Sauer (1998) and Vaughan Williams (1999) for comprehensive surveys]. Given that the great majority of people in developed countries participate in gambling, at least occasionally, iii and that gambles often involve large stakes, ${ }^{\text {iv }}$ a model specification that can explain the outcomes in actual gambling markets seems perhaps more important than one that can explain the risk attitudes of small samples of students ${ }^{v}$ who, as we show below. 
would for some typical parameter estimates reported not gamble at actuarially unfair odds.

Given this background, the purpose in this paper is to consider the implications of a different parametric specification of CPT for gambling over mixed prospects. This is because the standard parametric specification of CPT based on power value functions is not appropriate for explaining gambling outcomes. In particular power utility violates the assumption of loss aversion for low enough stakes, (also pointed out by Köbberling and Wakker (2005), Schmidt and Zank (2005) and Law and Peel (2005)). Consequently any optimal model of gambling based on power value functions (e.g. Bradley (2003)) will imply violation of the assumption of loss aversion. There are also a number of other reasons outlined below to suggest that the power function is also not consistent with other empirical evidence. As a consequence we specify a bounded value function. (Also suggested by Köbberling and Wakker (2005) and Giorgi and Thorsten Hens (2005) in different contexts). This specification has a number of interesting and new implications in the gambling context. In particular, (a) if stakes are not too large the assumption of ultimate bounded ness of the value function will imply a minimum in the indifference curve in expected return-win probability space, for a given sise stake (b) the indifference curve will exhibit an asymptote, typically at very small probabilities, indicating that the agent would turn down a bet involving the possibility of an infinite gain; (c) though depending on the degree of risk aversion assumed over gains, the asymptote can occur at any probability in the $0-1$ 
range; (d), in the absence of probability distortion agents will, paradoxically, ultimately accept very large bets on odds-on chances at actuarially unfair odds ; (e) If the agent is sufficiently risk-averse over gains and risk-seeking over losses they can bet on odds on favourites although everywhere loss averse.

(f) Our parameterizations can simultaneously account for gambling on unlikely gains and the Allais paradox behavior. This is not the case with the standard parametric specification.(see Neison and Stowe (2002)).

Our parametric specification of the assumption of boundedness of the utility function allows us to choose the degree of loss aversion exhibited by agents over small and large stake symmetric gambles. Varying the different parameters, namely the degree of risk-aversion over gains and risk-seeking over losses, the degree of loss aversion or the probability weighting function over gains and losses, allows us to explain both gambling on favoured outcomes and longshots and hence contribute towards an explanation of the stylized empirical outcome of the favourite-longshot bias observed in most gambling markets. (see e.g. see Sauer (1998) and Vaughan Williams (1999), Cain, Law and Peel (2003))

The rest of the paper is structured as follows. In Section two we consider the implications of the CPT model for the shape of the indifference curve between expected-return and win-probability for mixed prospects. Section three develops further implications by assuming a particular parametric form of the KahnemanTversky function, and Section four contains a brief conclusion. 


\section{The Indifference Curve between Expected-return and Win-probability}

Defining reference point utility as zero, for a gamble to occur in CPT we require expected utility or value to be non-negative:vi

$$
E U=w^{+}(p) U^{r}(s o)-\mathrm{w}^{-}(1-p) U^{l}(s) \geq 0
$$

where the win-probability is given by $p$, and the functions $w^{+}(p)$ and $w^{-}(1-p)$ are non-linear s-shaped probability weighting functions. $U^{r}(s o)$ is the value derived from a winning gamble, where $o$ are the odds and $s$ the stake. $U^{l}(s)$ is the disutility derived from a losing gamble.

From (1) the optimal stake is such that $\frac{\partial E U}{\partial s}=0$ so that

$$
\frac{w^{+}(p)}{p}(\mu-p) U^{r^{\prime}}\left(\frac{s(\mu-p)}{p}\right)=w^{-}(1-p) U^{l^{\prime}}(s)
$$

where the expected return from a unit gamble, $\mu$, is defined as

$$
\mu=p(1+o)
$$

A bet is defined to be actuarially fair when $\mu=1$.

From (2) we have that $s=s(\mu, p)$ if $E U \geq 0$. Substituting $s=s(\mu, p)$ into (1) gives expected value, $E U$, as a function of $\mu$ and $p$, and hence an indifference map in $(\mu, p)$ space may be obtained by differentiating (1) with respect to $p$ and equating to zero, in order to find the combinations of expected return, $\mu$, and probability, $p$, between which the bettor is indifferent.

This produces: 


$$
\begin{aligned}
& \frac{d E U}{d p}=\frac{\partial w^{+}(p)}{\partial p} U^{r}(s o)-\frac{\partial w^{-}(1-p)}{\partial p} U^{l}(s)-\frac{w^{+}(p) s \mu}{p^{2}} U^{r^{\prime}}(s o)+\left\{s \frac{w^{+}(p)}{p} U^{r^{\prime}}(s o)\right\} \frac{d \mu}{d p} \\
& +\left[\frac{w^{+}(p)}{p}(\mu-p) U^{r^{\prime}}\left(\frac{s(\mu-p)}{p}\right)-w^{-}(1-p) U^{l^{\prime}}(s)\right] \frac{d s}{d p}=0
\end{aligned}
$$

and hence, in view of (2), (4) reduces to

$$
\begin{aligned}
& \frac{d \mu}{d p}=\left\{1+o-\frac{\varepsilon^{g p} o}{\varepsilon^{u}}+\frac{\varepsilon^{l p} w^{-}(1-p) U^{l}(s) o}{\varepsilon^{u} w^{+}(p) U^{r}(s o)}\right\} \\
& \text { where } \varepsilon^{u}=\frac{s o U^{r^{\prime}}(s o)}{U^{r}(s o)}, \varepsilon^{g p}=\frac{\partial w^{+}(p)}{\partial p} \frac{p}{w^{+}(p)}, \varepsilon^{l p}=\frac{\partial w^{-}(1-p)}{\partial p} \frac{p}{w^{-}(1-p)}
\end{aligned}
$$

where $\varepsilon^{u}$ is the elasticity of $U(),. \varepsilon^{g p}$ is the elasticity of the probability weighting function over gains (strictly positive), and $\varepsilon^{l p}$ is its elasticity over losses (strictly negative).

Equation (5) also holds for any arbitrary fixed level of stake. We can simplify (5), for the purposes of exposition by noting from (1) that in order to gamble we require $\quad 1 \geq \frac{w^{-}(1-p) U^{1}(s)}{w^{+}(p) U^{r}(s o)}$. So that for the expected -probability frontier, $(\mu, p)$, where the agent is just indifferent between gambling and not gambling (5) simplifies to

$$
\frac{\mathrm{d} \mu}{\mathrm{dp}}=\left(1+o-o\left[\frac{\varepsilon^{\mathrm{gp}}-\varepsilon^{\mathrm{lp}}}{\varepsilon^{\mathrm{u}}}\right]\right)
$$


The expected return -probability frontier has to exhibit a positive slope in order to be able to explain gambling at unfair odds or to explain the favourite-longshot bias, since $\frac{d \mu}{d p}$ is observed to be positive over much of its range in real markets. We recall that in the early literature the explanation of the favourite-longshot bias assumed that agent's utility functions were convex. and so exhibited risk-loving behaviour. (see e.g. Ali (1987) ). In the CPT model agents will act as if riskloving, so that $\frac{d \mu}{d p}>0$, when the probability distortion is strong enough to dominate factors which militate against gambling, namely the concavity of the value function, loss aversion, and the fact that gambles are typically actuarially unfair at low probabilities.

From inspection of (5) (and (7)) we observe the precise form that this has to take. For the agent to appear as if risk-loving it is necessary that the sum of the elasticity's of the probability weighting functions are less than the elasticity of the value function over gains. In many of the experimental studies, based on student responses, the estimates of parameters of the elasticity's of power utility and weighting function violate this condition for gambling. (see e.g. (Camerer and Ho (1994) $\varepsilon^{u}=0.225, \varepsilon^{g p}=0.56$ (for small probabilities), Wu and Gonzalez (1996) $\varepsilon^{u}=0.5, \varepsilon^{g p}=0.71$, (for small probabilities).

The size of stake will also influence the slope of the indifference curve by, in general, changing the elasticity of the value function over gains, so that a lower (higher) stake size increases (decreases) the elasticity. It will also change the 
propensity to gamble, (from 5) as changing stake size changes the ratio of the utility loss to the utility gain from the gamble at given odds.

One interesting feature of the CPT model, as shown below in a parametric example, is that the slope of the indifference curve, $\frac{d \mu}{d p}$, can be negative at actuarially unfair odds, $\mu<1$. This is not possible in the standard expected-utility model, where $\frac{d \mu}{d p}<1$ and $\mu>1$ everywhere.

\section{A Parametric Example of the Kahneman - Tversky Model}

$\mathrm{K}$ and $\mathrm{T}$ assumed a power value function in their empirical work. However this functional form has a variety of limitations that make it unsuitable for analysis of gambling in general. The limitations of the power function are both empirical and theoretical and are as follows.

1. K and T (1992) assume that the utility or value function exhibits loss aversion so that the slope changes abruptly at the reference point. In particular, the function is postulated to fall roughly twice as fast over losses as it rises over gains, exhibiting diminishing sensitivity as the marginal impact of losses or gains diminishes with distance from the reference point In the case of a power value function, the assumption of loss aversion is violated for small-stake gambling, and the agent becomes infinitely gain loving as the stake approaches zero. Let the value function be 


$$
v(x)=\left\{\begin{array}{lll}
x^{\alpha} & x \geq 0 & (0<\alpha<1 \\
-\lambda(-x)^{\beta} & x<0 & (\lambda>0,0<\beta<1)
\end{array}\right.
$$

Now $\beta>\alpha$ is a necessary assumption in order to ensure that stake size is determinate

Loss aversion, defined for a symmetrical gamble as the ratio of the gain to the loss is given for the power utility as

$$
\frac{x^{\alpha}}{-\lambda(-x)^{\beta}}
$$

We observe from (8) that as stake size approaches zero the ratio becomes

infinitely large so that the agent violates the assumption of loss aversion (

See also e.g. Köbberling and Wakker (2004) and Law and Peel (2007))).

2. Some important experimental evidence is inconsistent with a power value function. Markowitz (1952), Biswanger (1980), Hershey and Shoemaker (1980) and Holt and Laury (2002) report evidence that increases in payoff levels increase risk aversion. In these experiments the probabilities, in a sequence of gambles, are kept fixed as agents choose between a gamble and its certainty equivalent (kept fixed) or between a "safer" and "more risky" gamble. Choices change significantly with size of payoff. With a power value function this would not occur. This result is particularly important in the case of Holt and Laury who use real payoffs as well as hypothetical payoffs. They find that risk aversion increases sharply as payoffs are scaled up.

3. Blavatsky (2005) shows that the Kahneman-Tversky parameterization cannot resolve the St. Petersburg paradox unless the power coefficient of the utility 
function is less than that of the probability weighting function. However, this implies that the agent cannot exhibit risk-loving behaviour, as shown above.

3. Neilson and Stowe (2002) show that parameters required of the power specification and weighting function cannot simultaneously resolve the Allais paradox and account for gambling at actuarially unfair odds.

Given these objections In order to generate further predictions from the analytical framework set out above, we specify a parametric form for the Kahneman Tversky model. Rather than the power form used by Kahneman and Tversky, this paper employs the expo-power function ( see Saha (1993)) with the advantage that it nests both the exponential and the power function..

$E U=w^{+}(p)\left(1-e^{-r \delta s^{n} o^{n}}\right)-w^{-}(1-p) \lambda\left(1-e^{-\delta s^{n}}\right)$

where $r, \delta$ and $\lambda$ are positive constants.

For $\mathrm{n} \leq 1$ the agent is everywhere risk-averse over gains and risk-seeking over losses as postulated by KT. Also as $\delta \rightarrow 0$ we obtain the power specification of $\mathrm{K}$ and $\mathrm{T}$.

The value function in (9) has upper and lower bounds as is commonly assumed, e.g. Markowitz (1952) and Machina (1982). This is a sufficient condition for the resolution of the St. Petersburg Paradox [see, e.g. Menger (1967) and Bassett (1997)]. 
For the expo-power value function in (9), the degree of loss aversion, (LA), is defined by the ratio of the utility gain to the utility loss from a symmetric gamble, given by

$L A=\frac{\left(1-e^{-r \delta s^{n}}\right)}{\lambda\left(1-e^{-\delta s^{n}}\right)}$

Unlike the power value function the degree of loss aversion varies as stake size changes. As stake size approaches zero, the assumption of loss aversion requires that $\frac{r}{\lambda}<1$, and as it becomes large that $\frac{1}{\lambda}<1$. In order to ensure that $\frac{\partial L A}{\partial s} \leq 0$, so that the degree of loss aversion does not decrease with an increase in stake size, which would be counter intuitive, we require in general that $\frac{d \frac{U^{r}(s)}{U^{l}(s)}}{d s}<0$, which for $L A<1$, implies that $\frac{\partial U^{r}(s)}{\partial s}<\frac{\partial U^{l}(s)}{\partial s}$ for all s, which is consistent with the definition of loss aversion of Benartzi and Thaler (1995) and Köbberling and Wakker (2005)). For the exponential function this implies the additional requirement that $r \geq 1$.

Differentiation of (9) with respect to stake size gives us the optimal stake size, s, as

$$
s=\left[\frac{\ln \frac{w^{+}(p) r o^{n}}{w^{-}(1-p) \lambda}}{\delta\left(r o^{n}-1\right)}\right]^{\frac{1}{n}}
$$

with the second order condition

$$
\text { ro }^{\mathrm{n}}-1>0
$$


From the numerator of (11) a necessary condition for optimal stake size to be positive is that

$$
\frac{w^{+}(p) r o^{n}}{w^{-}(1-p) \lambda}>1
$$

This condition is precisely that required to undertake gambles with the power value formulation of $\mathrm{KT}$, but in that model optimal stake size is indeterminate.

Peel and Law (2007) pointed out that (13) can hold for odds on favourites when the gamble is actuarially unfair if $\mathrm{n}$ is small enough. As $\mathrm{n}$ becomes smaller the agent becomes more risk-averse over gains and more risk-loving over losses.

We also note that there are important implications of varying stake size. As stake size approaches zero, employing L'Hopitals rule, the agent will gamble if

$$
\frac{o^{n} w^{+}(p)}{w^{-}(1-p)} \geq \frac{\lambda}{r}
$$

This condition will be met for standard specifications of the weighting function as odds become large. Consequently the model implies agents will gamble at small enough stakes without violating the assumption of loss aversion.

In Figures 1(a) and 1(b) we plot the probability weighting function employed and its elasticity, $\left(\varepsilon^{g p}\right)$ over gains for the parameter values of Tversky and Kahneman (1992)], to illustrate their numeric values over the probability range, (employing alternative functional forms such as that of Prelec (1998)or Wu and Gonzalez (1996) made no qualitative difference to our analysis). 
The ratio of the weighting functions, $\frac{w^{+}(p)}{w^{-}(1-p)}, \quad$ is a key determinant of whether to gamble from (1) and their impact, relative to the zero probability distortion-free case, is given by $\frac{w^{+}(p)}{w^{-}(1-p)}-\frac{p}{1-p}$. This is plotted in Figures 2(a) and 2(b). We observe that the elasticity of the probability weighting function becomes infinitely large as $p$ approaches 1 , and is less than one when $p=0$.

We observe from Figure 2(a) that the probability weighting function enhances the attraction of longshot gambles per se, but diminishes the attraction of more favoured outcomes, with the cross-over occurring at probabilities of around 0.45. When probability distortion over gains exceeds that over losses, the cross-over can occur at much higher probabilities, illustrated in Figure 2(b). vii

For the exponential value function the slope of the indifference curve is given by

$$
\frac{d \mu}{d p}=\left\{1+o-e^{g p} \frac{\left(e^{r \delta s^{n} o^{n}}-1\right) o^{1-n}}{r \delta n s^{n}}+\frac{e^{l p}}{r \delta n s^{n}} \lambda e^{\delta s^{n}\left(r o^{n}-1\right)}\left(e^{\delta s^{n}}-1\right) \frac{w^{-}(1-p)}{w^{+}(p)}\right\}
$$

Note from (15) that as $o \rightarrow \infty$, then $\frac{d \mu}{d p}$ will ultimately become negative (due to the third and fourth terms increasing at a greater rate than the second-recall $e^{\mid p}$ is negative). In this case the bounded ness of the value function ultimately dominates the probability weighting function, so that there is a range of behaviour not obtainable in previous analysis (see e.g. Prelec's (2000, p.90)).

Also, note that increasing stake size will ultimately lead to $\frac{d \mu}{d p}<0$, (due to the third and fourth term) and this may occur over the whole of the probability range 
so that the agent will again appear to behave as a expected utility maximizer, so long as $\mu>1$ which will be the case for large enough stakes.

As stake size becomes small the elasticity of the value function approaches $n$ so that $\frac{d \mu}{d p}>0$ from (15) assuming any feasible elasticities of the weighting function.

There are two further implications of the property of the expo-power function that it is bounded from above and below.

Let the upper bound limit be unity (so $\mathrm{U}^{r}\left(\mathrm{so}^{\mathrm{n}}\right) \rightarrow 1$ as $\mathrm{so}^{\mathrm{n}} \rightarrow \infty$ ). The agent would then turn down an infinite gain gamble if

$$
\frac{w^{+}(p)}{w^{-}(1-p)}<U^{\prime}\left(s^{n}\right)
$$

Consequently, there is a win-probability threshold beyond which infinite gain bets will be turned down. The precise threshold will depend on particular parameter values, as illustrated below, but can occur even with small stakes. This is one implication of boundedness. A second one is that if bet size becomes very large, so that $\mathrm{U}^{r}\left(\mathrm{so}^{\mathrm{n}}\right) \rightarrow 1$ and $\mathrm{U}\left(\mathrm{s}^{\mathrm{n}}\right) \rightarrow \lambda$ so that the agent will gamble if

$$
\frac{w^{+}(p)}{w^{-}(1-p)}>\frac{\lambda}{1+\lambda}
$$

As a consequence, the agent could gamble at actuarially unfair odds at some large enough stake. Clearly such gambles are less likely to be observed if the degree of loss aversion for large stake gambles is itself large. 
Some of the above possibilities are illustrated in Figures $3(a)-4$ with $n=1$ for convenience. In Figure 3(a) expected utility is plotted against win-probability when the stake is set at its optimal value so $\frac{\partial E U}{\partial s}=0$, the degree of loss aversion is as postulated by Kahneman and Tversky, and the probability weighting function has the parameter estimates suggested in some of the experimental literature. The agent is observed gambling on a longshot where the expected loss per unit staked is 0.45 , so $\mu=0.55$. The distortion to probabilities caused by the probability weighting function overcomes the disinclination to gamble caused by the degree of loss aversion, so that the agent bets on longshots.

In Figures 3(b), 3(c) and 3(d) we plot the indifference curves between expected return and win-probability for a small constant $s \delta$. ${ }^{\text {vii }}$ Figure $3(\mathrm{~b})$ illustrates that $\frac{d \mu}{d p}$ can be negative, when expected returns are less than unity, a feature that cannot occur in an expected-utility model, and that the indifference curve has a maximum in the favourite end of the spectrum at better than actuarially fair odds. From Figures 3(c) and 3(d) we observe that the indifference curve exhibits both a minimum, and an asymptote, so that the agent turns down a gamble with infinite expected return, at an extremely small probability. In this case, the boundedness of the value function ultimately "overpowers" the probability weighting function, contrary to previous models in the literature.

In Figure 4 we plot the indifference curve between expected return and winprobability for a large $s \delta$. The key features are that the asymptote now occurs at a higher win-probability, and the indifference curve is negatively sloped 
throughout its range. The interaction of high stakes and the curvature of the value function dominate the influence of the probability weighting function so that the agent has an indifference curve which is observationally equivalent to an expected utility maximiser.

By choice of $s \delta$ and other parameter values we can position the asymptote at any win-probability. For example, using the exponential value function, with parameters $r=45, \lambda=90, \delta=0.0001$, and the probability weighting functions of Kahneman and Tversky (1992), with parameters of 0.61 for gains and 0.69 for losses, we calculate that in order to bet $\$ 10$, with win-probability of 0.5 , the agent would need to win at least $\$ 18.13$ (plausibly less than that of the students in the Kahneman-Tversky experiments). In addition, this agent would accept a bet to win infinity or lose $\$ 100$ at win probability of $0.5(E U=0.093)$, unlike the expected-utility maximizer, who would (absurdly) reject this gamble, as demonstrated by Rabin (2000). Indeed, our agent would accept this $\$ 100$ gamble if the potential gain were more than $\$ 336.1$. However, this Kahneman-Tversky agent would reject a bet to win infinity or lose $\$ 10$ at a win-probability of 0.02 or less. Consequently seemingly reasonably well calibrated CPT models can also exhibit seemingly absurd behaviour similar to that of the expected-utility maximiser.

\section{Kahneman-Tversky agents with less loss aversion}

The degree of loss aversion assumed by Kahneman and Tversky, based on student responses, arguably seems to large to be widely applicable to other agents. ${ }^{\text {ix }}$ 
Leroy (2003) makes the point in the context of more traditional asset markets. He questions who would actually turn down a bet to win $\$ 11$ or lose $\$ 10$ at a winprobability of 0.5 (as the Kahneman-Tversky students do), noting that such gambles have risk-return characteristics superior to those of the daily returns on common stocks, which individuals generally find acceptable.

With this point in mind, we relax the degree of loss aversion over small stakes. ${ }^{\mathrm{X}}$ In addition we allow the probability distortion over losses to be slightly greater than over gains, as suggested by the empirical work of Jullien and Salanie (2000).

In Figures 5(a) we plot over the win-probability range typically observed in horseracing $(0.01-0.7)$, the indifference curve between expected return and win probability for the agent making a 10 unit stake. It has the shape of the typical favourite-longshot bias reported for the US and UK horse -racing markets. In addition, the probability weighting function induces a maximum in the indifference curve for extreme favourites, requiring rates of return greater than unity.

The parameter values chosen for this agent are such that she will exhibit the typical pattern of preferences outlined by Allais (1953) for gambles involving millions as well as those found by Kahneman and Tversky who employed moderate (thousands) rather than large scale gains ${ }^{\mathrm{xi}}$. Whilst exhibiting the "Allais Paradox" the agent will nevertheless will gamble at even odds at roulette and horse racing or bet on the NFL. 
In Figure 5(b) we illustrate the expected return-win probability indifference curve that might depict a typical student. Whilst she too will exhibit the preferences found by Allais and Kahneman and Tversky in experiments she will not gamble on favourites. She exhibits the degree of loss aversion suggested by $\mathrm{K}$ and $\mathrm{T}$ over small stakes and requires exactly to win 30 to gamble 10 on a $50-50$ chance. Nevertheless she will buy lottery tickets.

Finally in Figure 6 we illustrate the agent betting on an odds on favourite when the agent becomes very risk-averse over gains and very risk-seeking over losses although everywhere loss averse. We illustrate this point assuming no probability distortion. The parameters are $r=25, \lambda=50, n=0.25$. We suppose for illustrative purposes that $\mu=0.94737$, the expected return to a one-unit gamble at roulette. In figure 6 we plot the relationship between expected utility and the objective win probability when stake size is optimal and given by (11).

\section{Conclusion}

Whilst the standard parametric specification of CPT by KT can provide an explanation of gambling on longshots (low probability bets) at actuarially unfair odds, gambling on more favoured outcomes is inexplicable. Given that in actual economies a sizeable proportion of agents gamble and most of the money bet is on favourites this is a major limitation of the model. Whilst $\mathrm{K}$ and $\mathrm{T}$ assumed power value functions in their experimental work this is unsuitable for the 
simultaneous analysis of gambling outcomes and the Allais paradox as noted by Neilson and Stowe (2002), who stated that the most obvious conclusion of our work is that alternative functional forms are needed. In this paper we assume an exp-power value function and show that gambling over all outcomes at actuarially unfair odds can be explained. In addition we can simultaneously explain the Allais paradox with the chosen parameter values, as shown in our calibrated examples in the last section.

We show that boundedness of the value function in CPT theory implies that the indifference curve between expected-return and win-probability will exhibit a minimum at low win-probabilities, because the shape of the value function dominates the probability weighting function. Also, a maximum will occur at high win-probabilities.

The analysis in the paper shows how KT agents with different degrees of loss aversion, probability distortion or risk-aversion or risk-loving over gains and losses can optimally bet at actuarially unfair odds on probabilities spanning the whole probability range. Naturally an aggregate model of gambling outcomes based on KT agents would have to embody heterogeneous agents rather than a representative frame work as in Ali(1977). However such a model is consistent with a major feature of experimental work. For example Harrison et al. (2007) who suggest that one should not readily assume homogenous risk preferences for the population. In fact aggregate models based on heterogeneous agents would seem necessary to simultaneously explain the favourite long shot bias or reverse favourite long shot bias observed in different counties or between different gambling activities. Peel and Law (2007a) is one such attempt. 


\section{REFERENCES}

Allais, Maurice (1953), "Le Comportement de l'Homme Rationnel devant le Risque: Critique des Postulats et Axiomes de l'Ecole Américaine," Econometrica $21,503-546$

M. Allais and O. Hagen (1979), editors, Expected Utility Hypotheses and the Allais Paradox. Dordrecht: D. Reidel.

Ali, M. M (1977). 'Probability and Utility Estimates for Racetrack Bettors', Journal of Political Economy, 85, pp.803-815.

Bassett, G.W. (1987), "The St. Petersburg Paradox and Bounded Utility", History of Political Economy, 1987, v. 19, n. 4, reprinted in Expected Utility, Fair Gambles and Rational Choice, O.F. Hamouda and J.C.R. Rowley editors, Elger, 1997.

Benartzi, Shlomo and Richard H. Thaler (1995), "Myopic Loss Aversion and the Equity Premium Puzzle," Quarterly Journal of Economics 110, 73-92.

Binswanger,H.P.(1980) "Attitude Toward Risk::Experimental Measurement in Rural India."Journal of Agricultural Economics,62,395-407.

Blavatsky, Pavlo R. (2005), "Back to the St. Petersburg Paradox?", Management Science, vol. 51, n⿳⺈, pp. 677-678 [

Bradley, I. (2003) "The representative bettor, bet size and prospect theory"' Economics Letters, 78, 409-413. 
Cain, M , Law, D. and D. A Peel, (2003) "Bias and Insider Trading in a Variety of Betting Markets", The Bulletin of Economic Research , 55(3),263-274.

Camerer, Colin F. and Teck-Hua Ho (1994). Violations of the betweeness axiom and nonlineraity in probability. Journal of Risk and Uncertainty, 8, 167-196.

Clotfelter, C.T. and Cook, P.J. (1989), Selling Hope: State Lotteries in America, Cambridge, MA: Harvard University Press.

Conlisk, J. (1993), "The Utility of Gambling", Journal of Risk and Uncertainty, 6, 255-275.

Cornish, D.B. (1978), Gambling: A Review of the Literature, HMSO, London.

De Giorgi, E. and Hens, T. (2005) Making Prospect Theory Fit for Finance NCCR-Finrisk and IEW University of Zurich

Friedman, M. and Savage, L.J. (1948), "The Utility Analysis of Choices Involving Risk," Journal of Political Economy, LV1, 279-304.

Harrison, G. W., J. List and C. Towe, (2007) 'Naturally Occurring Preferences and Exogenous Laboratory Experiments: A Case Study of Risk Aversion,' Econometrica, Vol. 75, No. 2, March, 433-58

Hershey, John C. and Shoemaker, Paul J.H. (1980),"Prospect theory's reflection hypothesis: a critical examination", Organizational Behavior and Human Performance, 25: 395-418. 
Holt, C.A. and Laury,S.K .(2002) "Risk Aversion and Incentive Effects",American Economic Review,97,1644-1655.

Jeffrey, R. C. (1983), The Logic of Decision, Second Edition, University of Chicago Press.

Jullien, B. and Salanie, B. (2000), "Estimating Preferences under Risk: The Case of Racetrack Bettors", Journal of Political Economy, 108, 503-530.

Kahneman, D. and Tversky, A. (1979), "Prospect Theory: An Analysis of Decision under Risk," Econometrica, 2, 263-91.

Köbberling, V. and Wakker,P. (2005), "An Index of Loss Aversion," Journal of Economic Theory, 122,119-131.

Law.D and Peel, D.A. (2007) "Gambling and Non-Expected Utility: The Perils of the Power Function", . Applied Economics Letters ,14, 79 - 82.

Le Roy, S. (2003), "Expected Utility: a Defense", Economics Bulletin, Vol. 7, No. $7,1-3$.

Machina, M.J. (1982), "Expected Utility" Analysis without the Independence Axiom", Econometrica, 50, 2, 277-324.

Menger, K. (1967), "The Role of Uncertainty in Economics", in Essays in Mathematical Economics in Honor of Oskar Morgenstern (ed. Martin Shubik), Princeton University Press.

Neilson, W. S. and Stowe, J. (2002),"A Further Examination of Cumulative Prospect Theory Parameterizations", Journal of Risk and Uncertainty, 24, 31-46. 
Peel, D.A. and Law, D. (2007) "Betting on odds on Favourites as an Optimal Choice in Cumulative Prospect Theory "Economics Bulletin, July.

Peel, D.A. and Law, D. (2007a) "Non-Expected Utility Models and Heterogeneity in Risk Attitudes: Towards an Explanation of Gambling Outcomes for Individual and Markets". Mimeo University of Lancaster

Prelec, D. (1998), “The Probability Weighting Function," Econometrica, 66, 497527.

Prelec, D. (2000), "Compound Invariant Weighting Functions in Prospect Theory", pp. 67-92 in Choices, Values, and Frames, (eds.) Daniel Kahneman and Amos Tversky, Cambridge University Press.

(1999) Pathological Gambling: A Critical Review. Committee on the Social and Economic Impact of Pathological Gambling, National Research Council.

Rabin, M (2000), "Risk Aversion and Expected-Utility Theory: A Calibration Theorem", Econometrica, 68, 5, 1281-1292.

Rabin, M. and Thaler, R. (2001), "Risk Aversion", Journal of Economic Perspectives, 15(1), Winter 2001, 219-232.

Saha, A. (1993), “Expo-Power Utility: A Flexible Form for Absolute and

Relative Risk Aversion," American Journal of Agricultural Economics, (75), 905-913.

Samuelson, P.A. (1963), "Risk and Uncertainty: A Fallacy of Large Numbers", Scientia, 153-158. 
Sauer, R.D. (1998), "The Economics of Wagering Markets", Journal of Economic Literature, XXXV1, 2021-2064.

Schmidt, Ulrich and Horst Zank (2005), "What is Loss Aversion?" The Journal of Risk and Uncertainty 30, 157-167

Starmer, C. (2000), "Developments in Non-Expected Utility Theory: The Hunt for a Descriptive Theory of Choice under Risk," Journal of Economic Literature, Vol. XXXV111, 332-382.

Starmer, C. and Sugden,R. (1989) "Violations of the independence axiom in common ratio problems: an experimental test of some competing hypotheses", Annals of Operations Research, 19,79-102.

Strumpf, K.S. (2002), "Illegal Sports Bookmakers" mimeo. University of North Carolina at Chapel Hill.

Thaler, R.H. (1985), "Mental Accounting and Consumer Choice", Marketing Science, 4, 199-214.

Tversky, A.and Kahneman, D. (1992), "Advances in Prospect Theory: Cumulative Representation of Uncertainty," Journal of Risk and Uncertainty, 5:4, 297-323.

Vaughan Williams, L. (1999), "Information Efficiency in Betting Markets: a Survey"', Bulletin of Economic Research, 53, 1-30.

The Wager (2000a), "The Prevalence of Problem Gambling: The British Experience", Gamble" 5, 32. Massachusetts Council on Compulsive Gambling. 
The Wager (2000b), "Stress, Anxiety, and Why Gamblers Gamble", 5, 27. Massachusetts Council on Compulsive Gambling.

Walther, H. (2002), "Economics of Gambling", mimeo., University of Economics, Vienna.

Wu, G. and Gonzalez, R. (1996), "Curvature of the Probability Weighting Function", Management Science, 42, 1676-1688. 
Figures 1 (a) -1(b)

\section{Shape and Impact of the Probability Weighting Function (PWF)}

(a) Probability Weighting Function over Gains

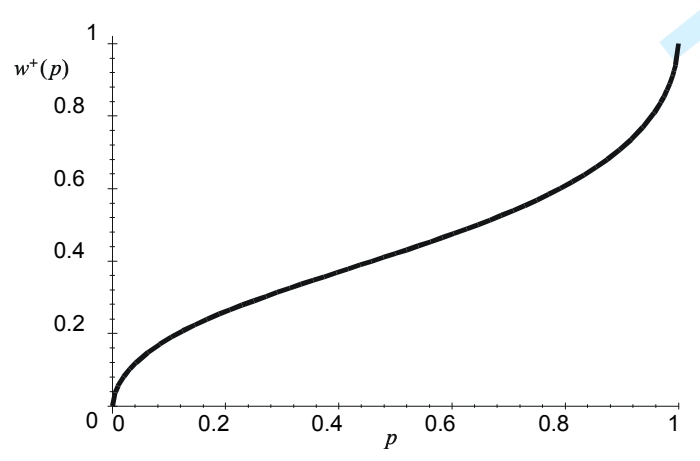

$$
w^{+}(p)=\frac{p^{\sigma}}{\left(p^{\sigma}+(1-p)^{\sigma}\right)^{\frac{1}{\sigma}}},
$$

$\sigma=0.61$ (Tversky and Kahneman (1992))

$p=0.9, \mathrm{w}^{+}(p)=0.712, p=0.5, w^{+}(p)=0.421$

$p=0.1, w^{+}(p)=0.186, p=0.001, w^{+}(p)=0.014$ (b) Elasticity of the PWF over Gains

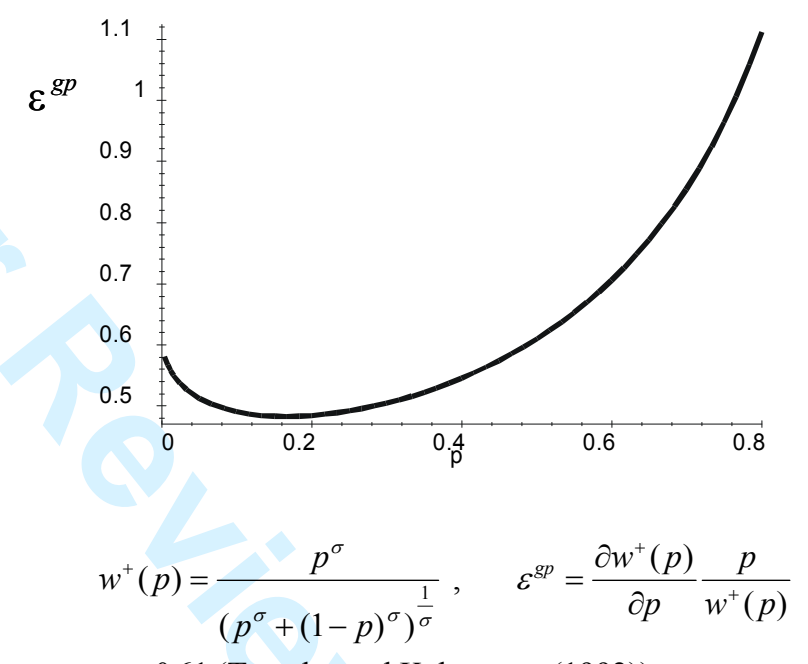

$\sigma=0.61$ (Tversky and Kahneman (1992)) 
Figures 2(a) -2(b)

\section{Impact of the Probability Weighting Function on Gambling}

(a) Impact of the PWF on the gambling decision

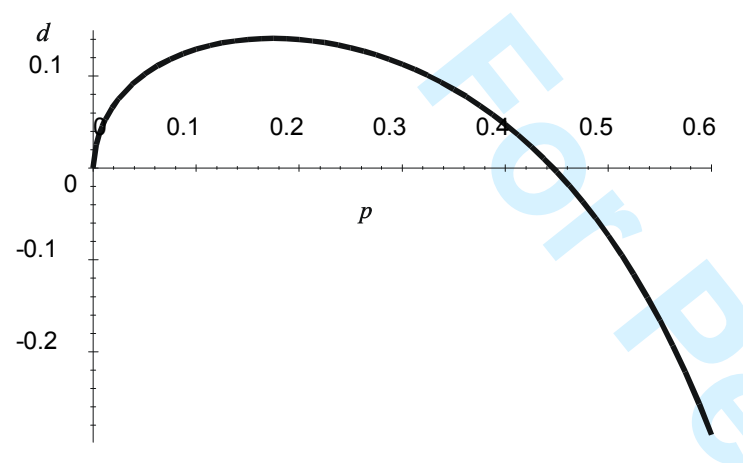

$d=\frac{w^{+}(p)}{w^{-}(1-p)}-\frac{p}{1-p}$

$w^{+}=\frac{p^{\sigma}}{\left(p^{\sigma}+(1-p)^{\sigma}\right)^{\frac{1}{\sigma}}}$

$w^{-}(1-p)=\frac{(1-p)^{\rho}}{\left(p^{\rho}+(1-p)^{\rho}\right)^{\frac{1}{\rho}}}$

$\sigma=0.61, \rho=0.69$ (Tversky and Kahneman (1992)) (b) Impact of the PWF on the gambling decision

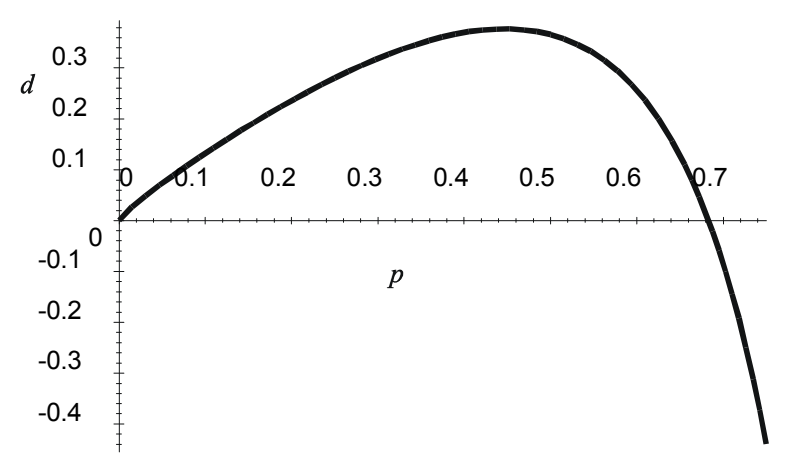

$$
\begin{aligned}
& d=\frac{w^{+}(p)}{w^{-}(1-p)}-\frac{p}{1-p} \\
& w^{+}=\frac{p^{\sigma}}{\left(p^{\sigma}+(1-p)^{\sigma}\right)^{\frac{1}{\sigma}}} \\
& w^{-}(1-p)=\frac{(1-p)^{\rho}}{\left(p^{\rho}+(1-p)^{\rho}\right)^{\frac{1}{\rho}}} \\
& \sigma=0.8, \rho=0.50
\end{aligned}
$$


Figures 3(a) -3(d)

\section{Expected Utility, Expected Return and Probability for CPT}

(a) Expected Utility-probability curve

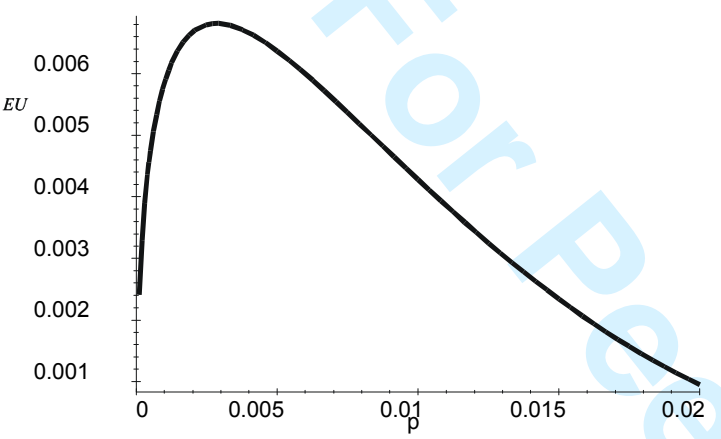

$E U=w^{+}(p)\left(1-e^{-r \delta s o}\right)-w^{-}(1-p) \lambda\left(1-e^{-\delta s}\right)$

$s=\frac{\ln \left[\frac{w^{+}(p) o r}{w^{-}(1-p) \lambda}\right]}{\delta(r o-1)}, \mu=0.55, r=45, \lambda=90$.

$w^{+}(p)=\frac{p^{\sigma}}{\left(p^{\sigma}+(1-p)^{\sigma}\right)^{\frac{1}{\sigma}}}, \sigma=0.61$,

$w^{-}(1-p)=\frac{(1-p)^{\rho}}{\left(p^{\rho}+(1-p)^{\rho}\right)^{\frac{1}{\rho}}}, \rho=0.69$. (b) $(\mu, p)$ indifference curve $0.000002 \leq p \leq 1$

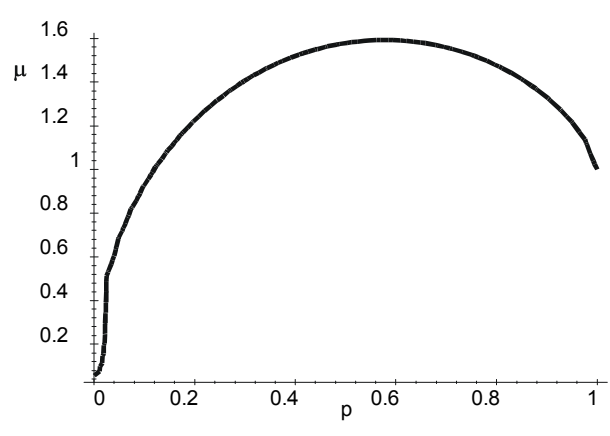

$E U=w^{+}(p)\left(1-e^{-r \alpha s o}\right)-w^{-}(1-p) \lambda\left(1-e^{-\alpha s}\right)=0$

$s=1, \alpha=0.000001, r=45, \lambda=90$.

$w^{+}(p), w^{-}(1-p)$ as in 3(a). (c) $(\mu, p)$ indifference curve :

(c)

$0.000001 \leq p<0.000002$ (d) $(\mu, p)$ indifference curve:

(d) )

$0 \leq p \leq 0.000001$

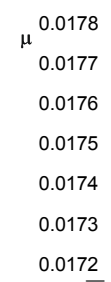

$\mu^{0.0178}$
0.0177
0.0176
0.0175
0.0174
0.0173
0.0172
0.017 E

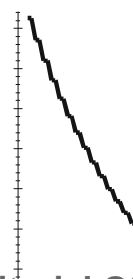

ditorial Offic 


\section{Figure 4}

Asymptote in Expected Return and Probability

(a) $(\mu, p)$ indifference curve in range $0 \leq p \leq 1$

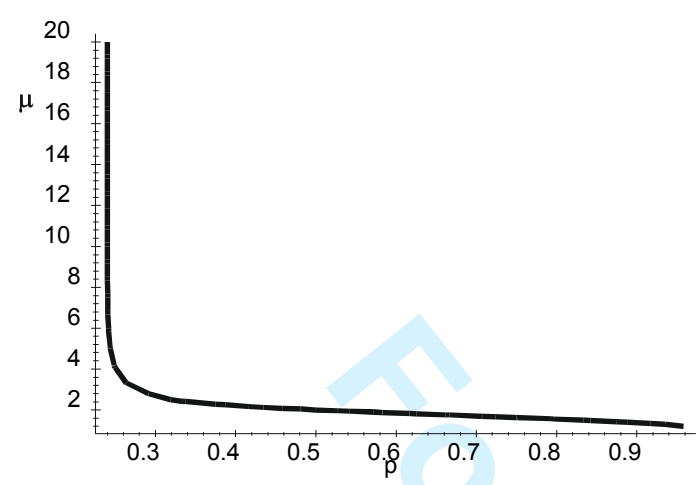

$$
\begin{aligned}
& E U=w^{+}(p)\left(1-e^{-r \alpha s o}\right)-w^{-}(1-p) \lambda\left(1-e^{-\alpha s}\right)=0 \\
& s=1, \alpha=0.000001, r=45, \lambda=90 \\
& w^{+}(p), w^{-}(1-p) \text { as in } 3(\mathrm{a}) .
\end{aligned}
$$




\section{Figures 5 (a) and (b)}

\section{Indifference curves for a Less Loss Averse Gambler and a "student"}

(a) $(\mu, p): 0.0001 \leq p \leq 1$

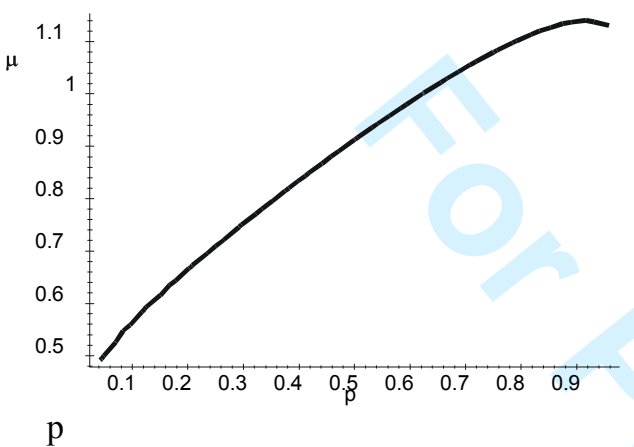

(b) $(\mu, p): 0.0001 \leq p \leq 1$

$\mu$

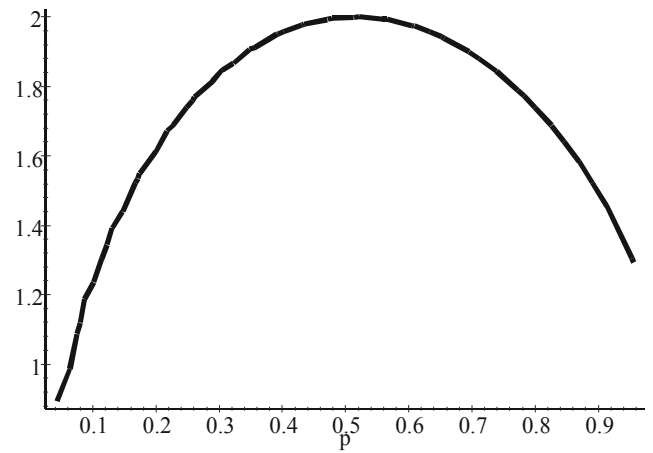

$$
\begin{gathered}
E U=w^{+}(p)\left(1-e^{-r \delta s o}\right)-w^{-}(1-p) \lambda\left(1-e^{-\delta s}\right)=0 \\
s=\frac{10}{1000000}, r \delta=3, r=10, \lambda=27.8 \\
w^{+}(p)=\frac{p^{\sigma}}{\left(p^{\sigma}+(1-p)^{\sigma}\right)^{\frac{1}{\sigma}}}, \sigma=0.61 \\
w^{-}(1-p)=\frac{(1-p)^{\rho}}{\left(p^{\rho}+(1-p)^{\rho}\right)^{\frac{1}{\rho}}}, \rho=0.69
\end{gathered}
$$

note: $\mathrm{s}=1$ denotes a 1 million stake in these figures

Figure 6 Plot of Expected utility and win probability 


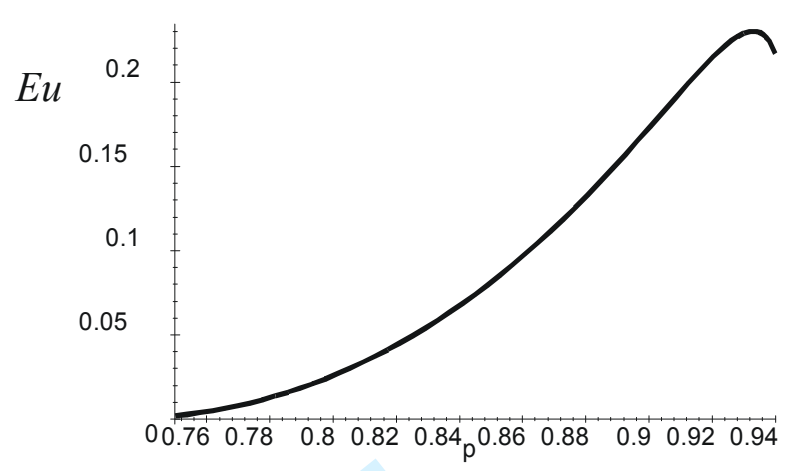

$\mu=0.94737, r=25, \lambda=50, n=0.25$ 


\section{Endnotes}

${ }^{\mathrm{i}}$ We are grateful to Robert Sugden for comments on an earlier version.

${ }^{\text {ii }}$ For instance the apparent preference of some agents for segregated gains reported by Thaler (1985, p. 203) whose survey evidence indicated that most people believe that a person would be happier to win $\$ 50$ plus $\$ 25$ in separate lotteries rather than $\$ 75$ in a single lottery. An excellent discussion of this experimental evidence can be found in Starmer (2000). Rabin (2000) provides further indirect support for CPT, in demonstrating that the assumption of global risk-aversion has implications for agents' preferences with respect to small and large gambles that appear untenable a priori. In particular, he shows that if an agent turns down a gamble to win $\$ 11$ or lose $\$ 10$, each with probability 0.5 , at all prevailing wealth levels, then she will also turn down a bet to win infinity or lose $\$ 100$, each with probability 0.5 . In addition, Rabin notes that the assumption of global risk-aversion implies that agents who turn down a gamble to lose $\$ 100$ or win $\$ 200$ with win-probability 0.5 , would turn down a sequence of $\mathrm{N}$ such bets, say, $\mathrm{N}=100$, as shown by Samuelson (1963). Again, this appears absurd a priori. As a consequence of these implications, Rabin suggests that economists should reject standard expected-utility theory in favor of some version of the non-expected utility model, such as that proposed by Kahneman and Tversky. 
iii The proportion of people reported as gambling is high and varies little between countries. For instance, in 1998 68\% of respondents in the United States reported gambling at least once in the previous year. Legal gambling losses in America totalled over $\$ 50$ billion, and illegal gambling has been estimated at over $\$ 100$ billion - greater than the estimated expenditure on illegal drugs [see e. g. Strumpf (2003), Pathological Gambling (1999), and The Wager (2000a)].

iv Strumpf (2003), in his study of six illegal bookmakers in New York City over the period 1995-2000 (two of which had turnover in excess $\$ 100$ million per annum), reports that average bet size was relatively large for these firms, averaging in excess of $\$ 1000$. We also note that observation of high rollers on odd/even bets at roulette is folklore.

${ }^{v}$ Of course, it is still the case that some economists explain gambling by invoking nonpecuniary returns such as excitement, buying a dream or entertainment [see e.g. Clotfelter and Cook (1989)]. However, there are convincing a priori and empirical reasons for giving little weight to this rationalization in general. Friedman and Savage (1948) provide one convincing a priori critique of the entertainment rationale. Subsequently a number of surveys of gamblers have been conducted in which respondents are asked to cite the main reasons why they gamble. The predominant response, usually by $42 \%-70 \%$, is for financial reasons - "to make money" [see e.g. Cornis (1978), and The Wager (2000 b)].

${ }^{\text {vi }}$ If we define the current level of wealth as $W$, and the level of utility associated with $W$ as $\bar{U}$ then the exponential utility function 
$U=\bar{U}+U(W+x)$

defines utility for increases in wealth above $W$, where $W+x$ is wealth measured from $W$ to $\infty$. We require that the marginal utility and the second derivative for an increase in wealth, $\frac{\partial U}{\partial x}>0, \frac{\partial^{2} U}{\partial x^{2}}<0$. For a decrease in wealth below $W$, we define the utility function as

$U=\bar{U}-U(W-x)$

where $\mathrm{W}-\mathrm{x}$ is wealth measured from 0 to $\mathrm{W}$. We require that the marginal utility and the second derivative for a decrease in wealth are both positive, as postulated by Kahneman and Tversky.

${ }^{x i}$ This possibility receives some support from the empirical analysis of race-track betting by Jullien and Sallanie (2000).

xii There is an observational equivalence between increasing (decreasing) $\mathrm{s}$ and decreasing (increasing) $\delta$ in this model. $\delta$ is a scale parameter.

${ }^{\text {ix }}$ The postulated degree of loss aversion is based partly on experimental evidence in which students required a "substantial" win of approximately $\$ 30$ in order to induce them to bet $\$ 10$ on a $50 / 50$ chance.

\footnotetext{
${ }^{\mathrm{x}}$ Note that in the exponential value function we can redefine $s$ as the percentage of wealth (by deflating by total wealth and redefining the parameters).

${ }^{\mathrm{xi}}$ In particular the agent prefers gamble A to B, C to D, E to F, G to H, I to J, K to L. where $\mathrm{A}$ is a certain 1 million, $\mathrm{B}$ is 5 million with probability $0.1,1$ million with probability 0.89 and zero with probability 0.01 . $\mathrm{C}$ is 5 million with probability $0.1, \mathrm{D}$ is
} 
1 million with probability 0.11 , E is 2,400 with certainty, $\mathrm{F}$ is 2500 with probability $0.33,2400$ with probability 0.66 and zero with probability $0.01, \mathrm{G}$ is 2500 with probability $0.33, \mathrm{H}$ is 2400 with probability 0.34 ., I is 3000 with certainty, $\mathrm{J}$ is 3000 with probability $0.8, \mathrm{~K}$ is 4000 , with probability 0.2 , $\mathrm{L}$ is 3000 with probability 0.25 . 